\title{
Amelioration by Idesia polycarpa Maxim. var. vestita Diels. of Oleic Acid-Induced Nonalcoholic Fatty Liver in HepG2 Cells through Antioxidant and Modulation of Lipid Metabolism
}

\author{
Na Li $\mathbb{D}^{1,2}$ Yi-ran Sun $\mathbb{D}^{1},{ }^{1}$ Li-bo He, ${ }^{1}$ Lei Huang, ${ }^{3}$ Ting-ting Li, ${ }^{1}$ Tao-yu Wang, ${ }^{1}$ \\ and Lin Tang $\mathbb{\circledR}^{1,3}$ \\ ${ }^{1}$ Key Laboratory of Bio-Resources and Eco-Environment of Ministry of Education, College of Life Sciences, Sichuan University, \\ Chengdu, 610065 Sichuan, China \\ ${ }^{2}$ Sichuan Testing Center for Biomaterials and Medical Devices, Chengdu, 610064 Sichuan, China \\ ${ }^{3}$ Institute of New Energy and Low-Carbon Technology, Sichuan University, Chengdu, 610065 Sichuan, China
}

Correspondence should be addressed to Lin Tang; tanglin@scu.edu.cn

Received 20 April 2020; Revised 1 June 2020; Accepted 11 June 2020; Published 21 October 2020

Guest Editor: German Gil

Copyright ( $) 2020 \mathrm{Na} \mathrm{Li}$ et al. This is an open access article distributed under the Creative Commons Attribution License, which permits unrestricted use, distribution, and reproduction in any medium, provided the original work is properly cited.

\begin{abstract}
Idesia polycarpa Maxim. var. vestita Diels (I. polycarpa) is well known as an edible oil plant which contains abundant linoleic acid and polyphenols. The objective of this study was to maximize the by-product of defatted fruit of I. polycarpa. We found that the fraction D of ethyl acetate extract (EF-D) contained more polyphenols, which contribute to its strong antioxidant activity by antioxidant assays (DPPH, ABTS, and FRAP). Meanwhile, EF-D showed a significant lipid-lowering effect on oleic acid- (OA-) induced hepatic steatosis in HepG2 cells through enhancing antioxidant activity, reducing liver damage, and regulating lipid metabolism, antioxidant, and inflammation-related gene expression. The SOD and T-AOC levels significantly increased, but the levels of MDA, AST, and ALT decreased obviously when treated with EF-D. In general, EF-D improved the antioxidant enzyme activities and decreased the hepatic injury activities. Besides, treatment with EF-D for NAFLD influenced lipid metabolism and inflammation by activating PPAR $\alpha$ which was associated with the increased expression of CPT1 and decreased expression of SCD, NF- $\kappa$ B, and IL-1. Moreover, EF-D improved the oxidative stress system through activation of the Nrf2 antioxidant signal pathways and upregulated its target genes of HO-1, NQO1, and GSTA2. The results highlighted the EF-D from the defatted fruit of I. polycarpa regarding lipid-lowering, proving it to be a potential drug resource of natural products for treating the nonalcoholic fatty liver disease (NAFLD).
\end{abstract}

\section{Introduction}

Nonalcoholic fatty liver disease (NAFLD) encompassed a broad-spectrum pathology from simple triglyceride (TG) deposition in hepatocytes to nonalcoholic steatohepatitis (NASH), liver cirrhosis, and even hepatocellular carcinoma (HCC) [1]. With the change of life, a more calorie diet and less exercise have caused a rise among the general population in recent years [2]. It has been proven that oxidative stress involved in the etiology of NASH caused an imbalance between prooxidant and antioxidant chemical species that led to oxidative damage of cellular macromolecules [3-7].

Related reports showed that the damage of the membrane system will lead to the increased oxygen pressure in NAFLD and can initiate an oxidative stress response. Furthermore, multiple metabolic pathways of NAFLD can be mediated by PPARs to regulate lipid metabolism, glucose metabolism, and immune pathways. At present, there is no specific drug for the effective treatment of NAFLD due to its unclear pathogenesis and "crosstalk" between multiple metabolic pathways $[8,9]$. Based on the understanding of the current 
situation of NAFLD, it is urgent to develop new drugs and explore new therapeutic ways.

Idesia polycarpa Maxim. var. vestita Diels (I. polycarpa), a member of the Salicaceae family and the only species of monotypic genus Idesia, is a common oil woody and edible plant distributed widely in East Asia, such as China, Japan, and Korea. Research concerning the use of I. polycarpa as a natural source of edible oil and dietary supplement increased gradually due to its various unsaturated fatty acids, such as linoleic acid and linolenic acid $[10,11]$. The relative report has been confirmed that the oil of its fruits is nontoxic and has anticarcinogenic and antidiabetic effects and antihypertensive properties [12,13]. Moreover, flavonoid and phenolic glycosides of I. polycarpa exhibited various biological activities, such as antioxidant, skin whitening, inhibition of platelet aggregation, and antiadipogenesis [14]. Previous researches demonstrated that the ethyl acetate extracts of I. polycarpa exhibited strong antioxidant [14], anti-inflammatory, and whitening activities in vitro and in vivo $[15,16]$.

Taken together, these researches showed that I. polycarpa could be regarded as having potential medicinal value as a natural product for its antioxidant and anti-inflammatory activity. In our study, we isolated the EF-D from the defatted fruit of I. polycarpa by high-speed counter-current chromatography (HSCCC). Besides, we investigated the treatment effect and mechanism of EF-D-alleviated OA-induced NAFLD in HepG2 cells by antioxidant activities, related enzyme activities, and related gene expression. Our research has achieved the utilization by-product of the defatted fruit of I. polycarpa and demonstrated its potential medical value for alleviating NAFLD.

\section{Materials and Methods}

2.1. Reagents. Analytical-grade methanol, ethanol, acetonitrile chloride hexahydrate, ferrous sulfate, sodium molybdate, sodium nitrite, sodium hydroxide, sodium carbonate, Folin-Ciocalteu reagent (FC), and DPPH (Swell Scientific Instruments Co. Ltd., Chengdu, China). Cell Counting Kit8 (CCK-8) was purchased from KeyGen Biotech (Jiangsu, China). Test kits for triglyceride (TG), aspartate aminotransferase (AST), alanine aminotransferase (ALT), malondialdehyde (MDA), superoxide dismutase (SOD), and total antioxidant capacity (T-AOC) were purchased from Nanjing Jiancheng Bioengineering Institute (Nanjing, China). BCA Protein Quantification kit was purchased from Thermo Fisher Scientific (Thermo, USA). Oleic acid (OA) and oil red O (ORO) were purchased from Sigma Chemicals Co. (St. Louis, MO). TRIzol reagent and SYBR Premix Ex Taq were obtained from Invitrogen and Takara, respectively.

2.2. Plant Material Preparation of Extracts. Fruits of Idesia polycarpa Maxim. var. vestita Diels (I. polycarpa, voucher specimen No. SZ 0071614) were collected from the local market (Guangyuan, Sichuan, China) and were identified by Jie Bai, School of Life Sciences, Sichuan University.

After being placed in the shade to dry up at a constant weight at room temperature, the fruits were ground and sieved with a 40-mesh sieve. Before analysis, the oil of sam- ples was removed by $n$-hexane extraction 3 times and the solution was pooled. After vacuum filtration, the filtrate was combined and dried under vacuum at $37^{\circ} \mathrm{C}$. The defatted powder was stockpiled at $-20^{\circ} \mathrm{C}$. Approximately $100 \mathrm{~g}$ of the defatted powder was weighed and extracted with $75 \%$ ethanol $(1: 40 \mathrm{~g} / \mathrm{mL})$ at $65-75^{\circ} \mathrm{C}$ for $4 \mathrm{~h}$. The extracts were filtered, and the filtrates were concentrated by using a vacuum rotary evaporator. Before use, the primary $75 \%$ ethanol extract (EE) was suspended in distilled water. The solutions were sequentially extracted by ethyl acetate for 4 times. Lastly, the ethyl acetate extracts (EAE) were evaporated to dryness at $50^{\circ} \mathrm{C}$.

2.3. Ultrahigh Performance Liquid Chromatography (UPLC) Analysis. The compounds present in EE and EAE were carried out on a Waters ACQUITY System focused instrument equipped with a binary high pressure pump, a photodiode array detector, a thermostatic column compartment, and an automated sample injector (Waters, Inc., America). Chromatographic runs were all performed using a reverse-phase column $(\mathrm{C} 18,250 \times 4.6 \mathrm{~mm}, 5 \mu \mathrm{m}$ particle size, Phenomenex, America). The mobile phase consisted of solvent A-acetonitrile, and solvent $\mathrm{B}-0.1 \%$ aqueous formic acid solution; the flow rate was $0.5 \mathrm{~mL} / \mathrm{min}$ and the column temperature was maintained at $40^{\circ} \mathrm{C}$ during the run. The elution program was 10\%-25\% A (0-1.0 min), 25\%-30\% A (1.0-2.0 min), 30\%-31\% A (2.0-2.4 min), $31 \%-32.5 \%$ A $(2.4-4.4 \mathrm{~min}), 32.5 \%-35 \% \mathrm{~A}$ (4.4-5.5 min), 35\%-10\% A (5.5-5.51 $\mathrm{min})$, and $10 \% \mathrm{~A}(5.51-$ $8.0 \mathrm{~min}$ ). Detection was performed at $280 \mathrm{~nm}$. The injection volume was $10 \mu \mathrm{L}$. All analyses were performed in triplicate.

\subsection{High-Speed Counter-Current Chromatography (HSCCC)} Separation of EAE. The EAE were separated by HSCCC. The peak fractions were collected manually according to the elution profile and evaporated under reduced pressure. Optimal two-phase solvent systems are evaluated with a partition coefficient $(0.2 \leq K \leq 5)$. The two-phase solvent systems ethyl acetate-n-butyl alcohol-water $=4: 1: 5,2: 3: 5$, and $3: 2: 5$ and $n$-hexane-ethyl acetate-methanol-water $=2: 5$ $: 2: 5,3: 2: 1: 5,3: 5: 3: 5$, and $4: 1: 1: 5, v / v / v / v$, were screened as follows: the two-phase solvent system was prepared by adding each solvent to a separatory funnel. After shaking and thoroughly equilibrating at room temperature, the upper phase and lower phase were then separated and degassed ultrasonically for $30 \mathrm{~min}$. The upper phase was used as the stationary phase while the lower phase as the mobile phase. The sample solution for HSCCC separation was prepared by dissolving $5 \mathrm{~g}$ of EAE in $20 \mathrm{~mL}$ of the lower phase. The multilayer coil column was entirely filled with the stationary phase at a flow rate of $30.0 \mathrm{~mL} / \mathrm{min}$. The apparatus was rotated at $800 \mathrm{rpm}$, then the mobile phase was pumped into the column at a flow rate of $4 \mathrm{~mL} / \mathrm{min}$ in the head totail elution mode. The mobile phase eluting at the tail outlet indicated that hydrodynamic equilibrium had been reached. Subsequently, $20 \mathrm{~mL}$ of sample solution was injected into the column. The detection wavelength was set at $280 \mathrm{~nm}$.

\subsection{Antioxidant Activities In Vitro}

2.5.1. Total Flavonoid (TFC) and Total Phenolic Content (TPC). The method used to determine total phenolic content 
was based on the TFC method reported elsewhere with proper modification. Briefly, $10 \mu \mathrm{L}$ extracts were mixed with $100 \mu \mathrm{L}$ FC reagent, and $90 \mu \mathrm{L} 10 \%$ sodium carbonate solution was added $5 \mathrm{~min}$ later. The mixture was incubated at $25^{\circ} \mathrm{C}$ for 40 min with constant oscillation. The observance was gauged at a $765 \mathrm{~nm}$ wavelength. Gallic acid was used as a standard $(0.002-0.025 \mathrm{mg} / \mathrm{mL})$. The content of phenolics was calculated from a regression equation $\left(y=3.381 x+0.038, R^{2}=\right.$ 0.9995 ) and expressed as $\mathrm{mg}$ gallic acid equivalent/g of defatted fruit (mg GAE/g). The total flavonoid content was determined based on a colorimetric method with aluminium chloride $[17,18]$. Briefly, the $20 \mu \mathrm{L}$ extracts $(0.1 \mathrm{mg} / \mathrm{mL})$ or rutin $(0-0.1 \mathrm{mg} / \mathrm{mL})$ was diluted in $60 \%$ ethanol solution and mixed with $30 \mu \mathrm{L}$ of $\mathrm{NaNO}_{2}(5 \%)$. After $6 \mathrm{~min}, 50 \mu \mathrm{L}$ of $10 \% \mathrm{AlCl}_{3}$ was added to the above mixture; subsequently, $100 \mu \mathrm{L}$ of $\mathrm{NaOH}(1 \mathrm{M})$ was added. After $15 \mathrm{~min}$, the absorbance values were measured at $510 \mathrm{~nm}$ and compared with $50 \%$ ethanol as a blank control. The total flavonoid content was calculated from a regression equation $(y=0.4196 x+$ $\left.0.002, R^{2}=0.9995\right)$ and expressed as rutin equivalents (RE) per $g$ of dry extract.

2.5.2. DPPH Radical Scavenging Assay. $100 \mu \mathrm{L}$ of the extracts at different concentrations $(6.25-150 \mu \mathrm{g} / \mathrm{mL}$, dissolved in $60 \%$ ethanol) was mixed with $100 \mu \mathrm{L}$ of DPPH solution $(0.1 \mathrm{mM}$, in $60 \%$ ethanol). VC at the same concentrations was mixed with $100 \mu \mathrm{L}$ of DPPH solution $(0.1 \mathrm{mM}$, in $60 \%$ ethanol). The mixed solution was allowed to stand for $30 \mathrm{~min}$ in the dark at $23-25^{\circ} \mathrm{C}$, after which the absorbance was measured at $517 \mathrm{~nm}$, with $60 \%$ ethanol as a blank control $[19,20]$.

2.5.3. ABTS Radical Scavenging. The stock solutions included $7.4 \mathrm{mM} \mathrm{ABTS}+$ solution and $2.6 \mathrm{mM}$ potassium persulfate solution. The working solution was then prepared by mixing the two stock solutions in equal quantities and allowing them to react for $12 \mathrm{~h}$ at room temperature in the dark. The solution was then diluted by PBS to obtain an absorbance of $0.7 \pm 0.02$ units at $734 \mathrm{~nm}$ using the microplate reader. $100 \mu \mathrm{L}$ of various concentrations $(6.25-120 \mu \mathrm{g} / \mathrm{mL}$, dissolved in ethanol) of the extracts was mixed with $100 \mu \mathrm{L}$ of the diluted ABTS + solution. The reaction mixture was incubated at $30^{\circ} \mathrm{C}$ for $30 \mathrm{~min}$ [21]. Then, the absorbance was taken at $734 \mathrm{~nm}$ using the microplate reader (SpectraMax M2, Molecular Devices, Sunnyvale, CA, USA). VC was used as a reference.

2.5.4. FRAP Assay. $25 \mu \mathrm{L}$ of different concentration extract solutions (dissolved in $60 \%$ ethanol) was mixed with $50 \mu \mathrm{L}$ of phosphate buffer saline (0.2 M, pH 6.6) and $25 \mu \mathrm{L}$ of $1 \%$ $(w / v) \mathrm{K}_{3} \mathrm{Fe}(\mathrm{CN})_{6}$ solution. After incubation at $50^{\circ} \mathrm{C}$ for $30 \mathrm{~min}, 50 \mu \mathrm{L}$ of $10 \%$ trichloroacetic acid (TCA) was added. Then, the upper layer was combined with a $60 \mu \mathrm{L} 0.1 \%$ $(w / v) \mathrm{FeCl}_{3}$ solution. The absorbance was analyzed at $700 \mathrm{~nm}$ (BHT was used as a positive control) [22-24]. Increased absorbance of the reaction mixture indicates a greater reducing power.

2.6. Cell Culture. Human hepatocellular carcinoma (HepG2) cells, obtained from American Type Culture Collection (HB8065 , VA, USA), were cultured in DMEM contained with $10 \%$ fetal bovine serum (FBS) (Gibco, USA) and 1\% antibi- otic (penicillin-streptomycin) (Gibco, USA) and incubated in a humid incubator at $37^{\circ} \mathrm{Cand} 5 \% \mathrm{CO}_{2}$. When reaching approximately $80 \%$ confluency, the cells were treated with $1 \mathrm{mM}$ oleic acid bovine (OA-BSA) complex (molar ratio $4: 1$ ) for $24 \mathrm{~h}$, then treated with different concentrations of EF-D for $24 \mathrm{~h}$.

2.7. Cell Viability Assay. $1 \times 10^{4}$ HepG2 cells/well were seeded in a 96-well plate for $24 \mathrm{~h}$, then treated with the EFD groups: cells were treated with 10, 20, 40, 60, 80, 100, 150,200 , and $400 \mu \mathrm{g} / \mathrm{mL}$ of EF-D (dissolved by DMSO), and the OA+EF-D groups: cells were treated with $(1 \mathrm{mM})$ OA followed by different concentrations of EF-D. Then, $10 \mu \mathrm{L}$ of Cell Counting Kit-8 assay (CCK-8) was added to each well and incubated at $37^{\circ} \mathrm{C}$ for $1 \mathrm{~h}$. Lastly, absorbance readings at $450 \mathrm{~nm}$ were obtained using a microplate reader.

2.8. Measurement of Protein Concentration. The cell lysate proteins were quantified by using a BCA protein assay kit. Briefly, after treatment with the drugs, the cells were harvested and washed twice by centrifugation (Centrifuge 5424 R, Eppendorf, Germany) with precooled PBS at $600 \times \mathrm{g}$ for $5 \mathrm{~min}$. The supernatant was discarded, and the cells were resuspended in $200 \mu \mathrm{L}$ of cell lysis buffer and incubated on ice for $10 \mathrm{~min}$. After the second centrifugation $(8000 \times \mathrm{g}$, $5 \mathrm{~min}$ ), the supernatants were transferred to a new centrifuge tube and placed on ice during protein level analysis using the BCA Protein Quantification Kit. The absorbance values were measured at $562 \mathrm{~nm}$ by using a microplate reader. The protein concentration was calculated from a regression equation $\left(y=0.0303 x+0.0997, R^{2}=0.9877\right)$ and expressed as $\mathrm{mg} / \mathrm{mL}$.

\subsection{Determination of Lipid Accumulation}

2.9.1. Measurement of Cellular Triglyceride (TG). Cells were collected (less than $6 \times 10^{6}$ cells) and mixed with $1 \mathrm{~mL}$ lysis buffer $(2: 1, v / v)$. The resulting mixture was shaken at room temperature (RT) for $20 \mathrm{~min}$ and then centrifuged $(500 \mathrm{rpm})$ for $10 \mathrm{~min}$. The bottom layer was collected and resuspended for analysis of TG. TGs were measured using an enzymatic method kit following the instructions of the manufacturer.

2.9.2. Qualitative and Quantitative Measurements of Steatosis. The qualitative measurement of lipid accumulation was stained by using ORO. Cells were washed with PBS three times and fixed in $4 \%$ paraformaldehyde at room temperature for $40 \mathrm{~min}$. Then, remove fixative and wash three times with PBS and stain with ORO for $30 \mathrm{~min}$ at RT. Removing the ORO solution, cells were washed with PBS three times, then were observed under a fluorescent inverted microscope $[25,26]$. Then, adding isopropanol to split them, absorbance reading at $492 \mathrm{~nm}$ was obtained using a microplate reader.

\subsection{Key Enzyme Measurement of Hepatic Function and Antioxidant Activities}

2.10.1. Determination of AST and ALT Activities. AST and ALT activities were determined by a commercial test kit regarding the manufacturer's instructions. The absorbance 
TABLE 1: Sequences of primers used in RT-qPCR.

\begin{tabular}{lrc}
\hline Gene & Forward primer $\left(5^{\prime}-3^{\prime}\right)$ & Reverse primer $\left(5^{\prime}-3^{\prime}\right)$ \\
\hline GAPDH & AACGACCCCTTCATTGACC & GACCACGACTCATACAGCAC \\
Nrf2 & GCTCAACTTGCATTAATTCGGG & CTCTTTTCGGAAGTGGATGACT \\
HO- 1 & TCTTCACCTTCCCCAACATTG & GTACTGTGGTTCCTGGTCTC \\
NQO1 & ATGGTCGGCAGAAGAGC & TGAAGTTAGGGTAGTAAAGG \\
GSTA2 & TGAGGAACAAGATGCCAAGC & GGAATAAAGGTCGAAGGGAGAC \\
PPAR $\alpha$ & TCATCTCCTACTGTCCCACG & CAGGACCGGAAGATTTGCATC \\
CPT1 & TCATCTCCTACTGTCCCACG & CATAAATACCGTCACCCTCGA \\
SCD & CCCTACGGCTCTTTCTGATC & GACAGTTTCTCTTCCCCTCATG \\
NF- $\kappa$ B & CGAGCTTGTAGGAAAGGACTG & CTGATGCTGGACTTACGACAC \\
IL- 1 & GTACATCCTCGACGGCATC & GACCAGAAAACCTCAAACTCCA \\
\hline
\end{tabular}

values were measured at $340 \mathrm{~nm}$ by using a microplate reader, and the activities of AST and ALT were expressed as $\mathrm{U} / \mathrm{L}$.

2.10.2. Measurement of MDA. The content of MDA from cell lysis was related to lipid peroxidation which was measured by a commercial test kit. The absorbance values were measured at $532 \mathrm{~nm}$ by using a microplate reader and the content of MDA expressed as $\mathrm{nmol} / \mathrm{mg}$ prot.

2.10.3. Measurement of SOD. SOD activity was measured by using a commercial test kit with reference to the manufacturer's instructions. The absorbance values were measured at $450 \mathrm{~nm}$ by using a microplate reader and the activity of SOD was expressed as $\mathrm{U} / \mathrm{mg}$ prot.

2.10.4. Measurement of T-AOC. T-AOC was measured by using a commercial test kit concerning the manufacturer's instructions. The absorbance values were measured at $593 \mathrm{~nm}$ by using a microplate reader and T-AOC was expressed as $\mu \mathrm{M} / \mathrm{mg}$ prot.

2.11. Reverse Transcriptase Polymerase Chain Reaction (RT$P C R)$. The total RNA of cells was isolated using a TRIzol lysis reagent (Qiagen Sciences, Germantown, MD), according to the instructions of the manufacturer. The mRNA was reverse-transcribed into cDNA with a reverse-transcription kit (Takara Bio Inc), employing a SuperScript One-Step RT-PCR kit (Invitrogen, Carlsbad, CA). RT-PCR products were run with a loading star (Dyne Bio, South Korea) on a $1 \%$ agarose gel. Relative expression levels were calculated using the $2^{-\Delta \Delta \mathrm{Ct}}$ method and were normalized to GAPDH levels. The primer sequences are listed in Table 1.

2.12. Statistical Analysis. The data were expressed as means \pm standard deviation (SD) of three replications per experiment. Analysis of variance (ANOVA) (SPSS15.0, SPSS Inc., Chicago, IL, USA) and GraphPad Prism5 software (GraphPad Software, USA) were used. Values of $p<0.05, p<0.01$ or $p<0.001$ were considered statistically significant.

\section{Results}

3.1. Selection of Active Parts. The compounds of EE and EAE from the defatted fruit of I. polycarpa were detected by UPLC (Figure 1(a)). We found that the activities of EAE were relatively stronger compared with $\mathrm{EE}$ which was consistent with previous reports. Base on this analysis, we establish a valid way to isolate and purify EAE for its utilization.

Our study confirmed the two-phase solvent system composed of $n$-hexane-ethyl acetate-methanol-water $(3: 2: 1: 5$, $v / v / v / v)$ as optimal for its appropriate $K$ values and the retention of the stationary phase (43.7\%). In the HSCCC separation, the fractions were separated in $100 \mathrm{~min}$ with a total mobile elution volume of $300 \mathrm{~mL}$ (Figure 1(b)). Four fractions were collected and detected by UPLC (Figure 1(c)). Fractions A of ethyl acetate extract (EF-A) and C (EF-C) were low in content and complex in composition. Therefore, we selected fractions B of ethyl acetate extract (EF-B), D (EF$\mathrm{D}), \mathrm{EE}$, and EAE for further antioxidant assays.

The TPC and TFC of four different extracts are shown in Table 2. Among the four different extracts, EF-D showed the highest total flavonoid content, followed by EAE, EE, and EF$B$. The phenolic contents of EE and EF-D are higher than others. In the DPPH scavenging assay (Figure 2(a)), the $\mathrm{IC}_{50}$ value (Table 2) (the concentration required scavenge $50 \%$ of radical) showed EF-D was the strongest activity than others. In the ABTS assay (Figure 2(b)), the activity was dosedependent in low concentrations, and the $\mathrm{IC}_{50}$ value was $\mathrm{VC}$ $>\mathrm{EE}>\mathrm{EF}-\mathrm{D}>\mathrm{EF}-\mathrm{B}>\mathrm{EAE}$. FRAP was associated with the reduction of ferric ions to ferrous ions. At the concentrations of $5-100 \mu \mathrm{g} / \mathrm{mL}$, the phenomenon of concentration dependence was obvious, and EF-D showed the highlight activity by evaluating the value of $A_{0.5}$ (Figure 2(c)). Comprehensively, EF-D was the strongest fraction in antioxidant activity compared to others and then was selected for lipidlowering study in vitro.

3.2. OA Induced Hepatic Steatosis and Cell Viability. The HepG2 cells were treated with $0.1-2 \mathrm{mM}$ concentration of $\mathrm{OA}$ for $24 \mathrm{~h}$ to induce hepatic steatosis. Compared to the control, it did not cause cytotoxicity to the cells when treated with 0.1-2 mM OA (Figure 3(a)). Cell viability reached a peak when treated with $1 \mathrm{mM} \mathrm{OA}$. The number of lipid droplets in 


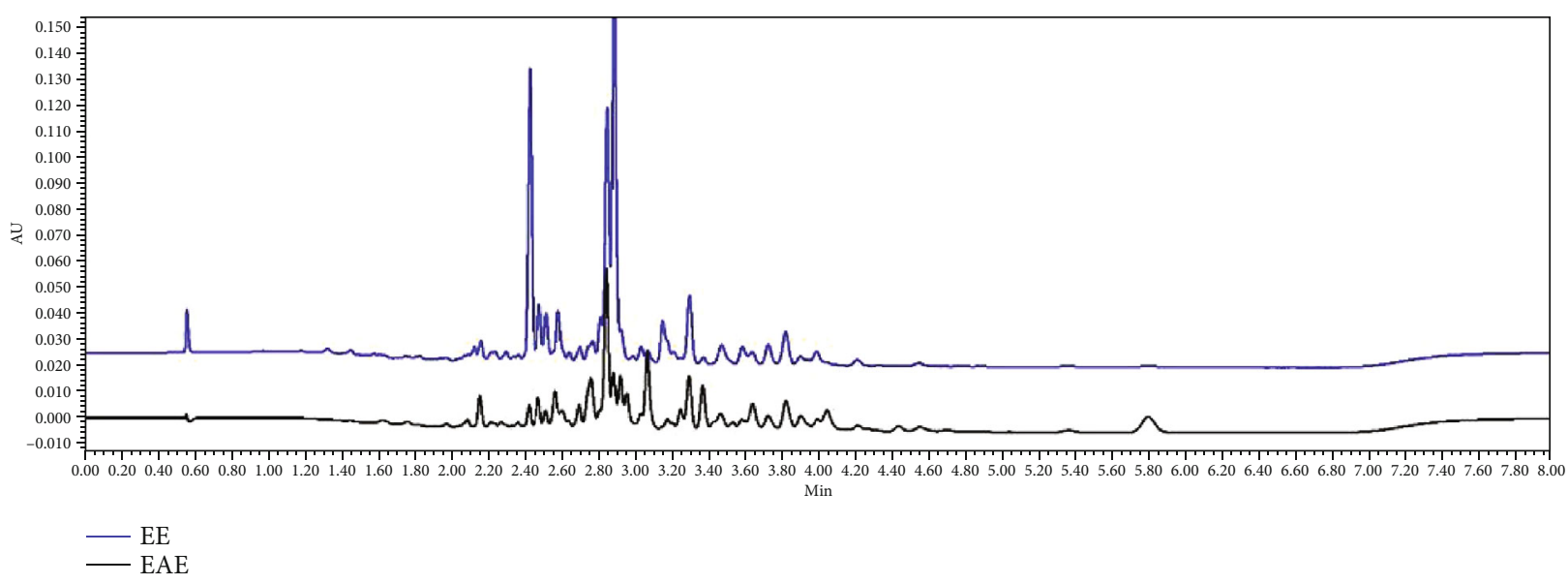

(a)

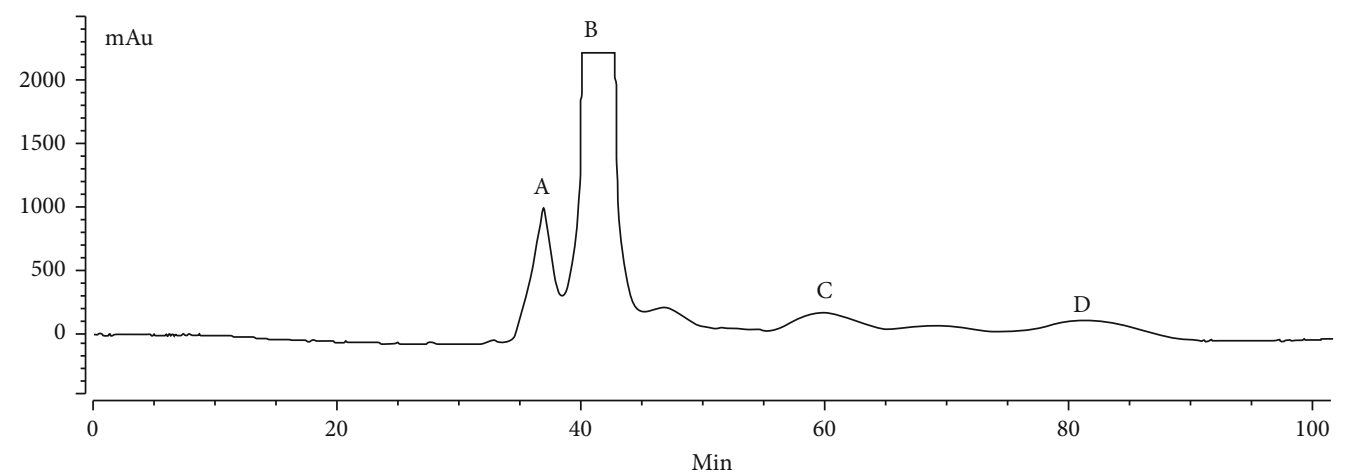

(b)
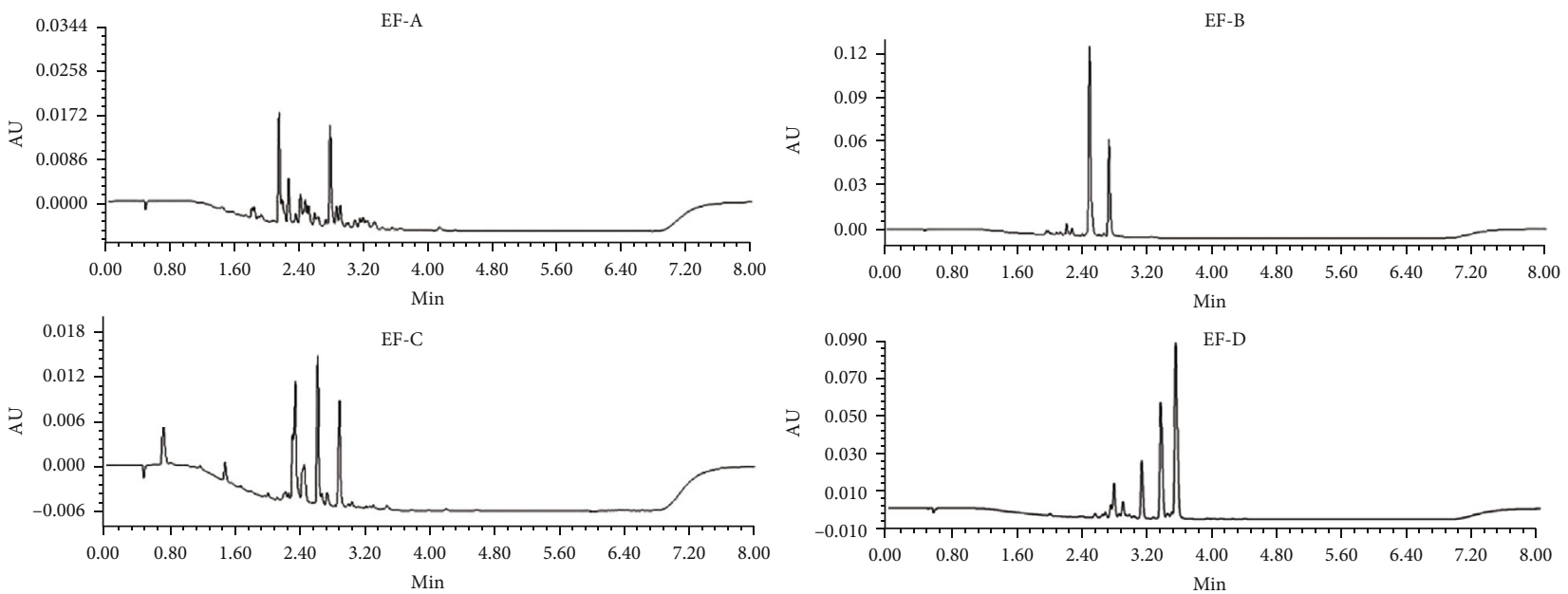

(c)

FIGURE 1: Chemical composition analysis: (a) UPLC chromatograms of EE and EAE detected at $280 \mathrm{~nm}$; (b) four fractions of EAE isolated by HSCCC; (c) UPLC chromatograms of EF-A, EF-B, EF-C, and EF-D detected at $280 \mathrm{~nm}$.

HepG2 cells was increased with the concentrations of OA (Figure 3(b)). Comprehensively, $1 \mathrm{mM} \mathrm{OA}$ was selected as a final concentration for inducing accumulation of lipid.

No evidence of toxicity of EF-D $(10-200 \mu \mathrm{g} / \mathrm{mL})$ was found in the HepG2 cells after treating for $24 \mathrm{~h}$. Cell toxicity of EF-D (100-400 $\mu \mathrm{g} / \mathrm{mL})$ was obvious when treated for $48 \mathrm{~h}$ (Figure $3(\mathrm{c})$ ). In addition, the viability was higher than the cells that were not treated with EF-D in a concentration- dependent manner (Figure 3(d)). Taken together, 10, 20, 40 , and $80 \mu \mathrm{g} / \mathrm{mL}$ of EF-D were chosen for further study.

3.3. Effects of EF-D on TG Accumulation in OA-Induced Hepatic Steatosis. To examine the lipid-lowering role of EF$\mathrm{D}$, we measured the TG accumulation in HepG2 cells. TG accumulation was significantly increased in the OA group compared with the control group, while EF-D inhibited TG 
TABLE 2: The content of TFC and TPC and antioxidant activity of EE, EAE, EF-B, and EF-D (IC $50, \mu \mathrm{g} / \mathrm{mL})$.

\begin{tabular}{lccccc}
\hline Samples & \multicolumn{2}{c}{$\mathrm{IC}_{50}(\mu \mathrm{g} / \mathrm{mL})$} & $\begin{array}{c}A_{0.5}(\mu \mathrm{g} / \mathrm{mL}) \\
\text { FRAP }\end{array}$ & $\begin{array}{c}\text { TFC } \\
\text { (mg RE/g extract) }\end{array}$ & $\begin{array}{c}\mathrm{TPC} \\
(\mathrm{mg} \text { GAE/g extract) }\end{array}$ \\
\hline EE & $101.715 \pm 2.007$ & $3.110 \pm 0.493$ & $37.972 \pm 1.579$ & $281.9 \pm 2.0$ & $195.536 \pm 2.0$ \\
EAE & $156.956 \pm 2.370$ & $7.071 \pm 0.849$ & $34.980 \pm 1.544$ & $335.3 \pm 25.9$ & $110.58 \pm 4.77$ \\
EF-B & $300.190 \pm 2.477$ & $5.915 \pm 0.772$ & $53.823 \pm 1.731$ & $106.4 \pm 113.7$ & $108.83 \pm 2.08$ \\
EF-D & $64.380 \pm 1.809$ & $5.531 \pm 0.743$ & $21.271 \pm 1.328$ & $397.1 \pm 5.0$ & $165.95 \pm 1.45$ \\
VC & $4.625 \pm 0.665$ & $2.613 \pm 0.417$ & nd & nd & nd \\
BHT & nd & nd & $75.688 \pm 1.879$ & nd & nd \\
\hline
\end{tabular}

$\mathrm{IC}_{50}$ : concentration that causes $50 \%$ scavenging in radical concentration; TFC: total flavonoid content; RE: rutin equivalents; TPC: total phenolic content; GAE: gallic acid equivalents; $n d$ : not determined. All values are represented as mean $\pm \mathrm{SD}(n=3)$.

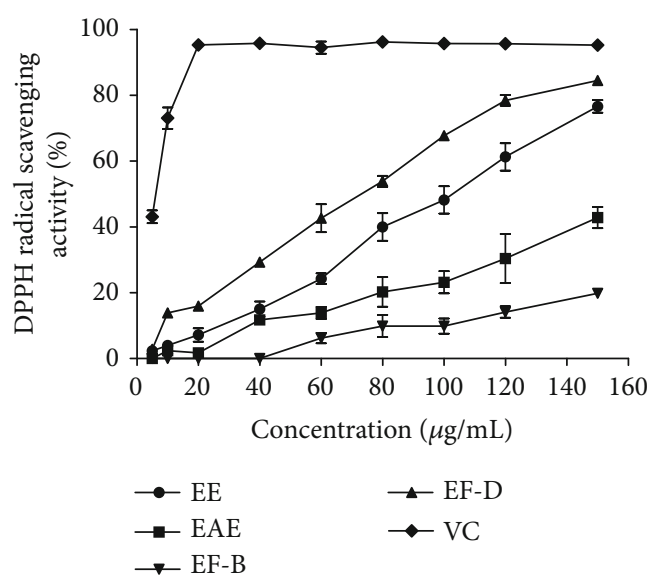

(a)

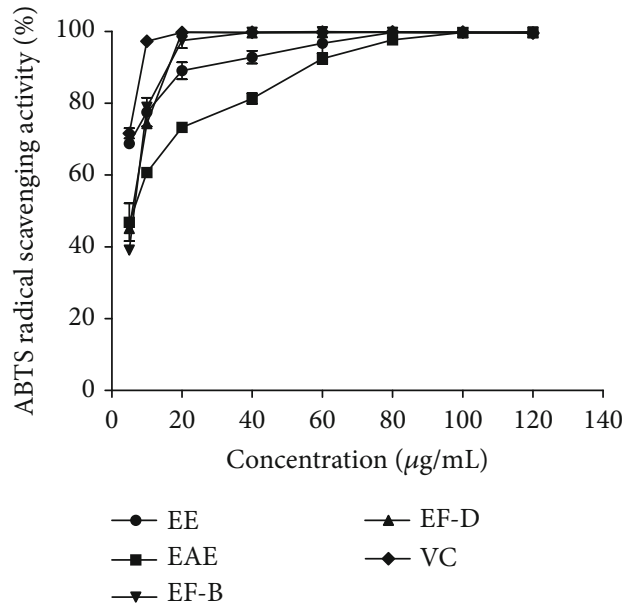

(b)

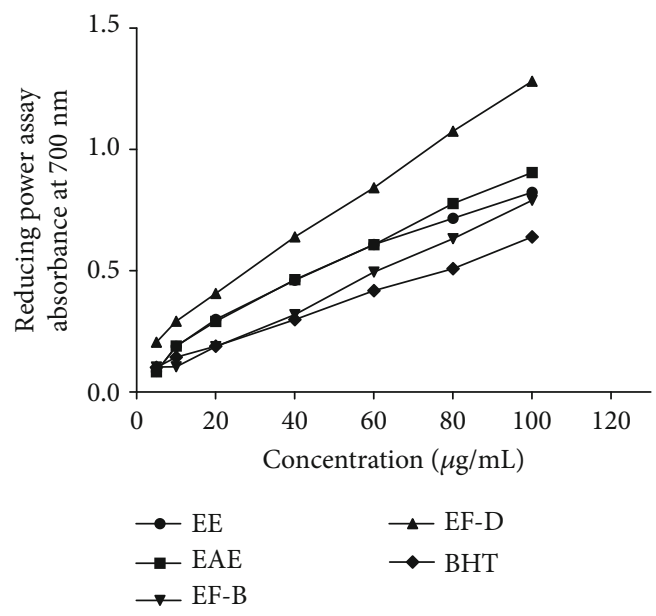

(c)

FIGURE 2: Effects of the antioxidant activities of the EE, EAE, EF-B, and EF-D: (a) DPPH assay; (b) ABTS assay; (c) FRAP assay. Data are presented as means $\pm S D(n=3)$. VC: vitamin C; BHT: butylated hydroxytoluene.

accumulation in a concentration-dependent manner when compared with the OA group. Rosiglitazone (ROSI) was recognized as the most effective and widely used medicine for NAFLD at present [27]. The inhibition of the lipid accumulation effect of EF-D was more sensitive to ROSI (Figure 4(a)). As shown in Figures 4(b) and 4(c), OA increased the intracellular lipid content when compared to the control. The number and size of lipid droplets were significantly reduced when EF-D was added compared with the OA group. Additionally, lipid deposits decreased by $10.2,17.5,24.7,38.7$, and $42.5 \%$ with $10 \mu \mathrm{M}(3.57 \mu \mathrm{g} / \mathrm{mL})$ ROSI and 10, 20, 40, and $80 \mu \mathrm{g} / \mathrm{mL}$ EF-D treatments. These 


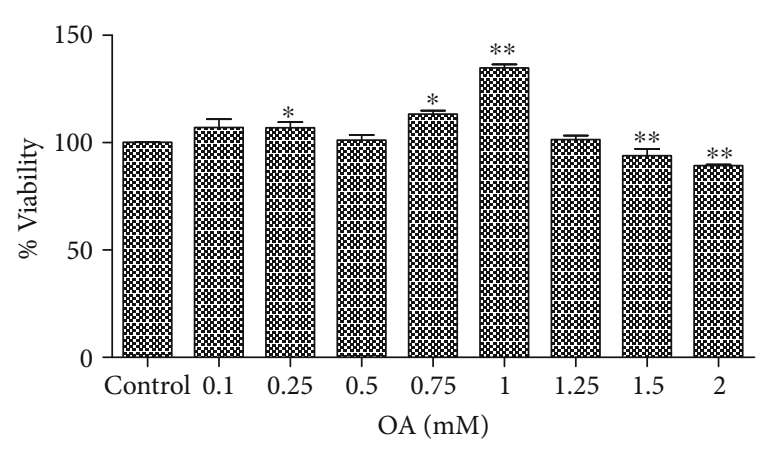

(a)

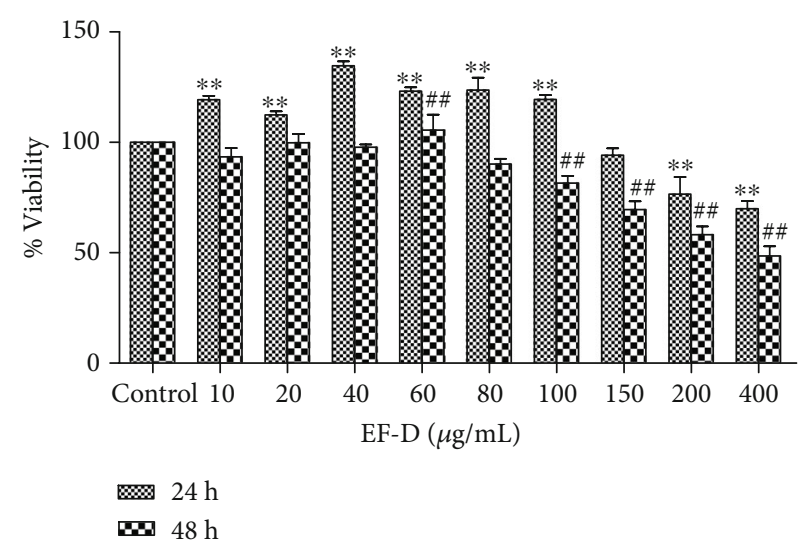

(c)

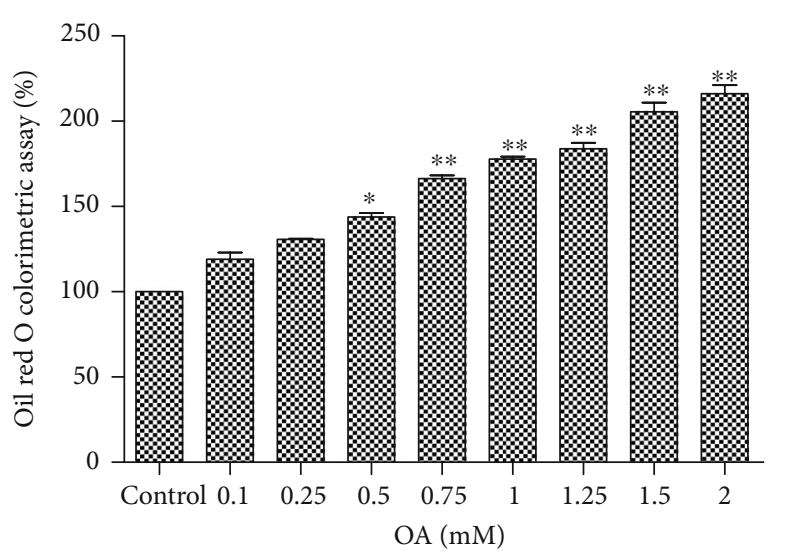

(b)

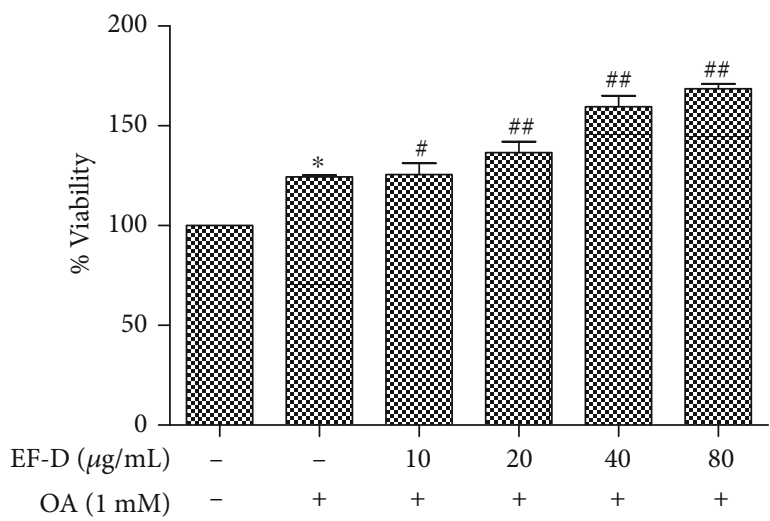

(d)

FIGURE 3: Cell viability and the TG accumulation effects of OA and EF-D:(a) HepG2 cells were treated with OA in different concentrations (0.1-2 mM) for $24 \mathrm{~h}$; (b) cells were stained with ORO; (c) cell viability of EF-D for $24 \mathrm{~h}$ and $48 \mathrm{~h}$; (d) cell viability of OA+EF-D. ${ }^{*} p<0.05$ and ${ }^{* *} p<0.01$ versus control. ${ }^{\#} p<0.05$ and ${ }^{\# \#} p<0.01$ versus OA.

data initially implied that EF-D had a regulatory lipid-lowing effect on OA-induced hepatic steatosis.

\subsection{Effects of EF-D on Key Markers in Responses to Oxidative} Stress. In this study, the activities of AST and ALT in the OA-induced HepG2 cells were higher than those of the corresponding control group, while treatment with EF-D observably suppressed the increase of ALT and AST in a concentration-dependent manner compared with the OA group (Figures 5(a) and 5(b)). The results demonstrated that EF-D reduced lipid accumulation by lowering liver injuryrelated enzyme activities. MDA content is commonly known as a marker of oxidative stress, and its level can directly influence the peroxidation of membrane. The levels of SOD and T-AOC can reflect the capacity of the antioxidant. As the results showed, EF-D dose-dependently decreased the content of MDA (Figure 5(c)) and elevated the levels of SOD (Figure 5(d)) and T-AOC (Figure 5(e)) in comparison to the OA group which further confirmed that EF-D alleviated lipid accumulation by decreasing enzyme activities associated with liver injury and enhancing antioxidase activities.
3.5. The Effects of EF-D on the Expression of Antioxidant Genes Related to Hepatic Steatosis. Nuclear factor erythroid2-related factor 2 (Nrf2), a key transcription factor in oxidative stress, can activate the expression of downstream related genes [28]. Our results demonstrated that EF-D attenuated lipid accumulation through increasing mRNA expression of Nrf2 and upregulating mRNA levels of its downstream oxidative response genes including heme oxygenase-1 (HO-1), $\mathrm{NAD}(\mathrm{P}) \mathrm{H}$ dehydrogenase, quinone 1 (NQO1), and glutathione S-transferase alpha 2 (GSTA2) (Figure 6(a)).

3.6. The Effects of EF-D on the Expression of Lipogenic Genes and Inflammatory Cytokine Genes Related to Hepatic Steatosis. Stearoyl coenzyme A desaturase (SCD) and carnitine palmitoyltransferase-1 (CPT1) are key genes for the lipid synthesis pathway and lipid catabolism pathway. Our results showed that EF-D downregulated SCD and upregulated CPT1 mRNA expression when compared with the OA group. Peroxisomal proliferator-activated receptor $\alpha(\operatorname{PPAR} \alpha)$ is closely related to several important metabolic pathways. Our results showed that EF-D upregulated the mRNA expression 


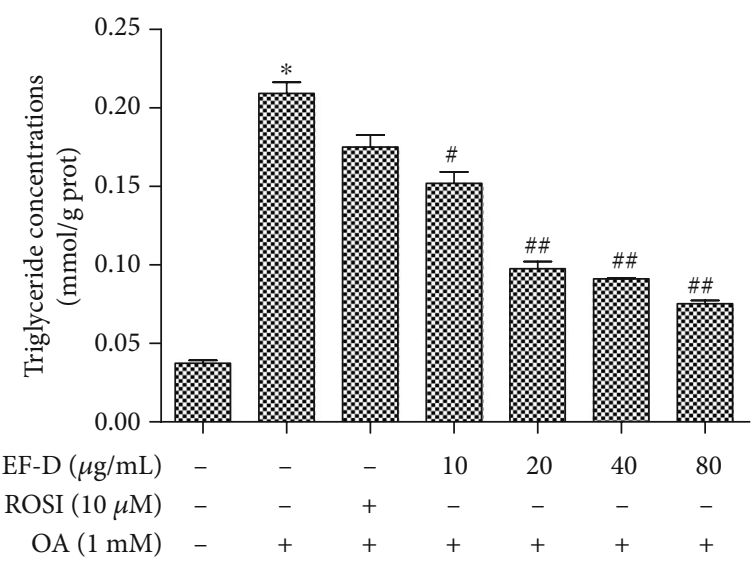

(a)

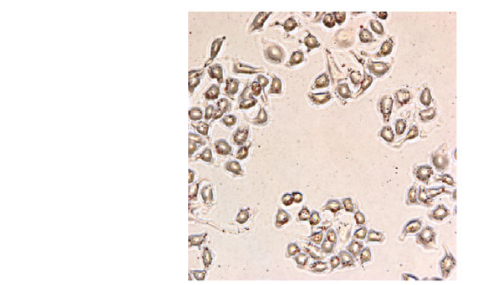

EF-D $(\mu \mathrm{g} / \mathrm{mL})$
ROSI $(10 \mu \mathrm{M})$
OA $(1 \mathrm{mM})$

0

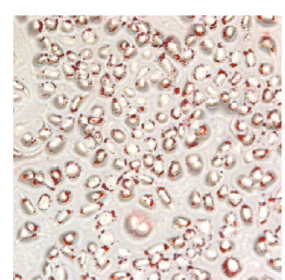

20

EF-D $(\mu \mathrm{g} / \mathrm{mL})$

ROSI $(10 \mu \mathrm{M})$

$\mathrm{OA}(1 \mathrm{mM})$

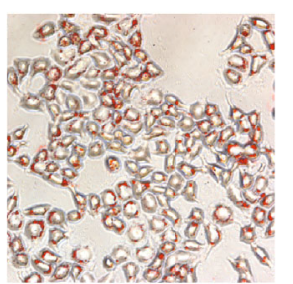

40

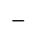

$+$

(b)

)

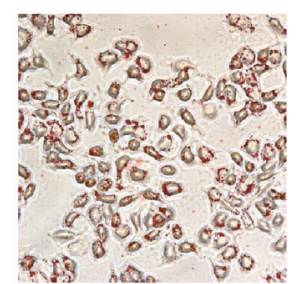

80

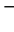

$+$

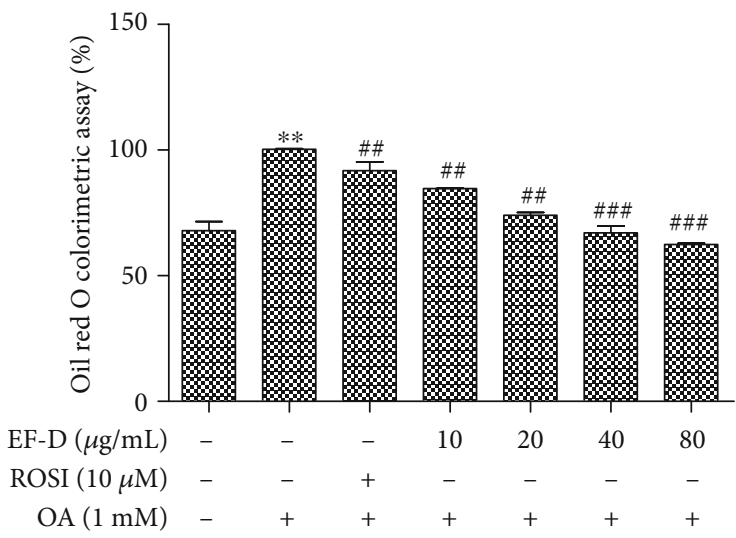

(c)

FIGURE 4: Lipid-lowering effect of EF-D: (a) total intracellular TG content; $(b, c)$ cells were stained with ORO and then quantitatively analyzed. Data are represented as mean $\pm S D(n=3) .{ }^{*} p<0.05$ and ${ }^{* *} p<0.01$ OA versus control. ${ }^{\#} p<0.05,{ }^{\# \#} p<0.01$, and ${ }^{\# \# \#} p<0.001$ $\mathrm{OA}+\mathrm{ROSI}(10 \mu \mathrm{M}), \mathrm{OA}+\mathrm{EF}-\mathrm{D}$ versus OA. 


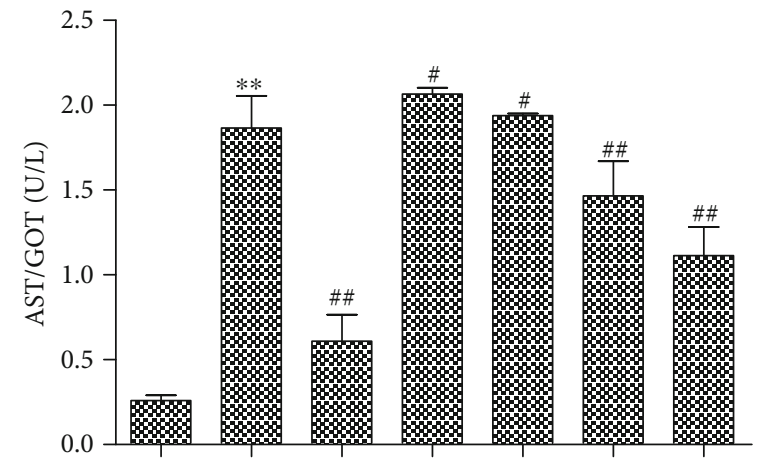

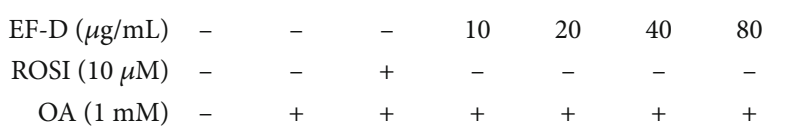

(a)

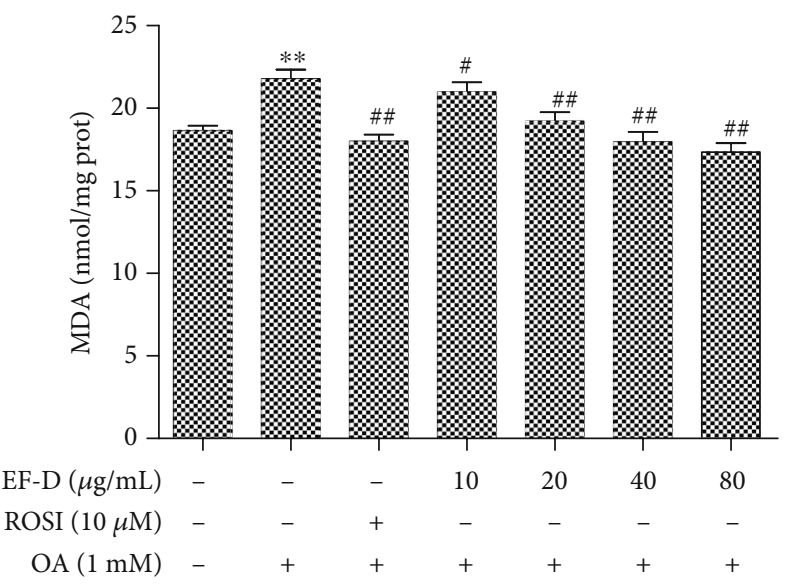

(c)

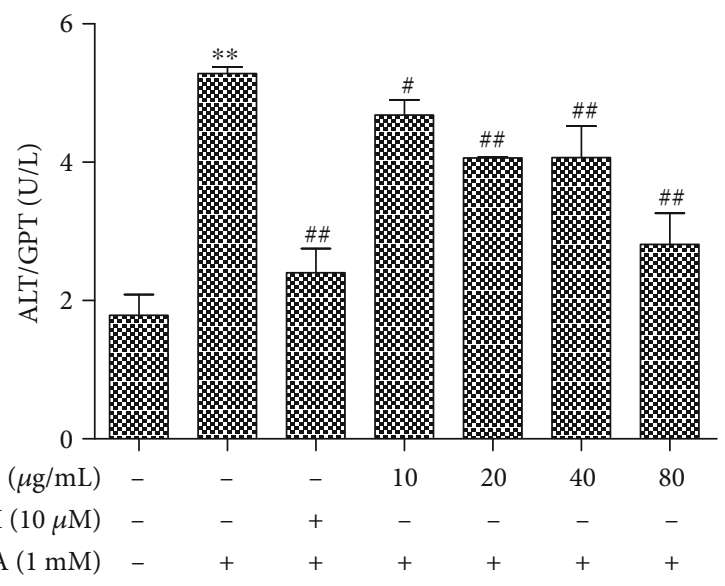

(b)

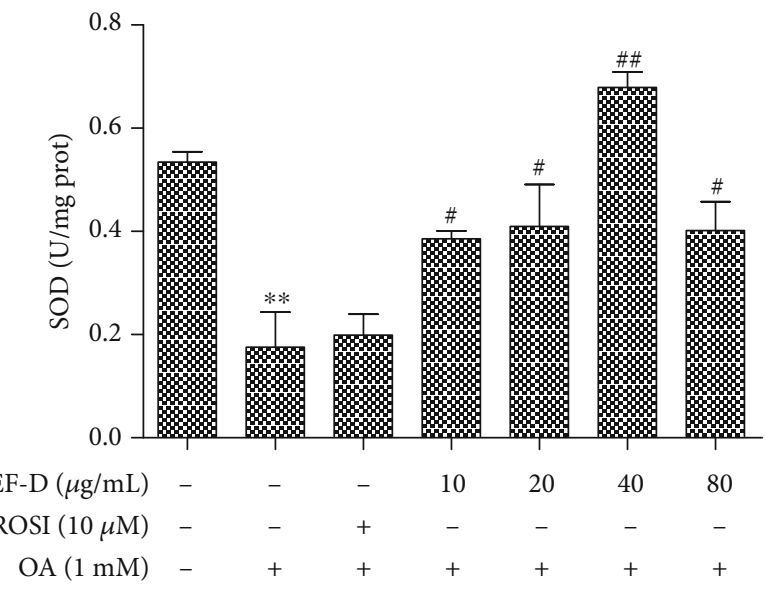

(d)

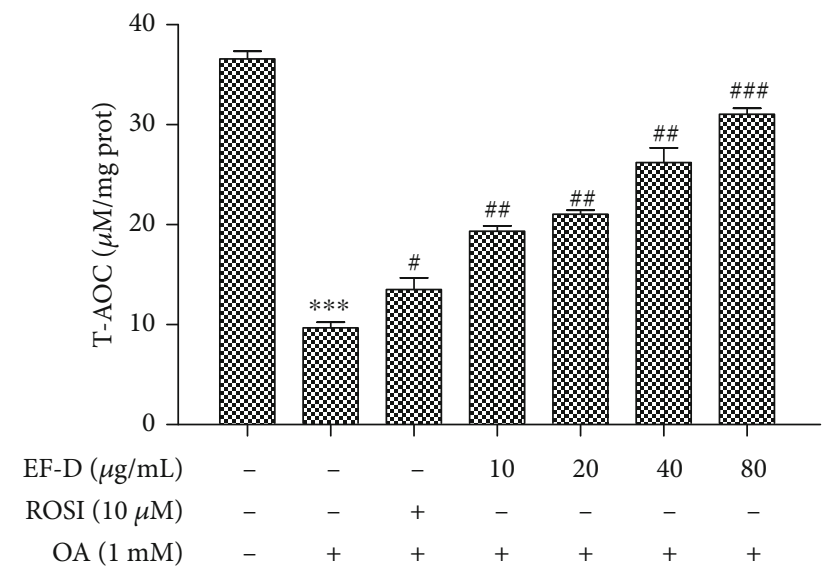

(e)

FIGURE 5: Effects of EF-D on key marker responses to oxidative stress: (a, b) AST and ALT activities of cellular supernatant; (c) the content of MDA in the supernatants of HepG2 cells lysates; (d, e) SOD and T-AOC activities in the supernatants of HepG2 cell lysates. Data are represented as mean $\pm S D(n=3) .{ }^{* *} p<0.01$ and ${ }^{* * *} p<0.001$ OA versus control. ${ }^{\#} p<0.05,{ }^{\# \#} p<0.01$, and ${ }^{\# \#} p<0.001$ OA+ROSI $(10 \mu \mathrm{M}), \mathrm{OA}+\mathrm{EF}-\mathrm{D}$ versus $\mathrm{OA}$.

of PPAR $\alpha$ which indicated EF-D regulated lipid metabolism by activating PPAR $\alpha$. (Figure 6(b)).

Nuclear factor kappa-B (NF- $\kappa \mathrm{B})$, tumor necrosis factor (TNF), and interleukin (IL) are the most critical factors associated with inflammation in NAFLD $[29,30]$. These findings indicated that EF-D distinctly downregulated the mRNA expression of NF- $\kappa \mathrm{B}$ and IL-1 compared with the OA group (Figure 6(c)). These results implied that EF-D may play a potential role in preventing the process of inflammatory cytokines. 


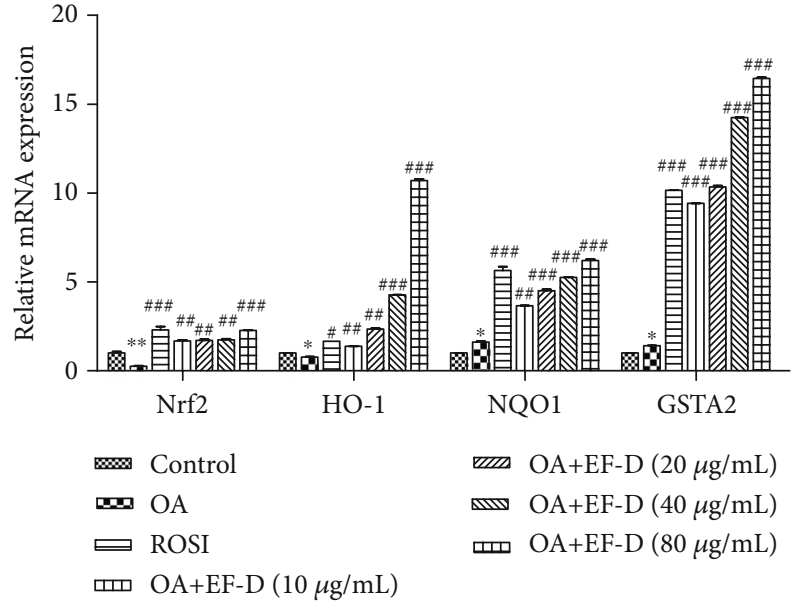

(a)

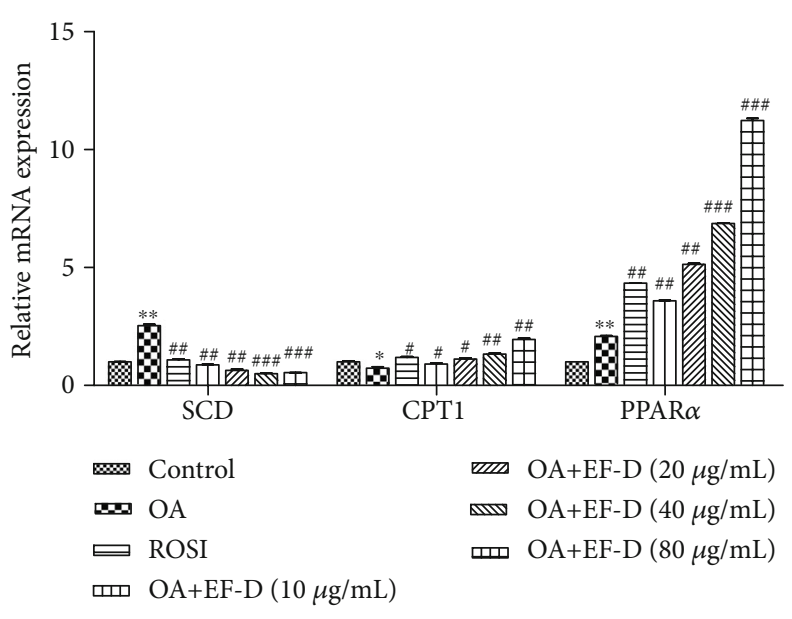

(b)

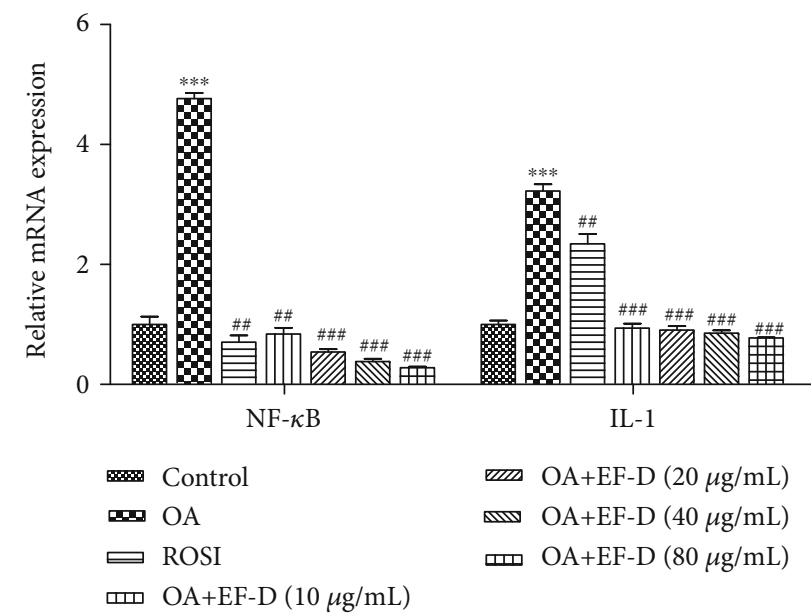

(c)

FIGURE 6: Effects of EF-D on the mRNA expression of oxidative stress and inflammatory cytokine genes: (a) Nrf2, HO-1, NQO1, and GSTA2; (b) SCD, CPT1, and PPAR $\alpha$; (c) NF- $\kappa$ B and IL-1 mRNA expression. Data are represented as mean $\pm S D(n=3) .{ }^{*} p<0.05$ and ${ }^{* *} p<0.01$ OA versus control. ${ }^{\# \#} p<0.01$ and ${ }^{\# \# \#} p<0.001 \mathrm{OA}+\mathrm{ROSI}$ and OA+EF-D versus OA.

\section{Discussion}

In the recent years, multiple natural phytochemicals, including polyphenols and carotenoid components from food, have been demonstrated to behave with beneficial effects on suppressing the development of NAFLD through improving hepatic glycolipid metabolism dysfunction [31, 32]. However, there are not many reports on treating NAFLD with natural products. The purpose of the study was to explore the antioxidant and lipid-lowering effect of I. polycarpa in vitro. It has been reported that many natural products that are rich in polyphenols and glycosides can repress lipid accumulation $[33,34]$. Our study found that the fragment EF-D from the defatted fruit of $I$. polycarpa can effectively ameliorate OA-induced NAFLD in HepG2 cells. Interestingly, we found that EF-D mainly contained $1-\left[\left(4^{\prime}-\mathrm{O}-(\mathrm{Z})\right.\right.$-p-coumaroyl $)-\beta$ D-glucopyranosyl]-oxy-2-phenol and 1-[( $4^{\prime}-\mathrm{O}-(\mathrm{E})-\mathrm{p}-\mathrm{cou}-$ maroyl)- $\beta$-D-glucopyranosyl]-oxy-2-phenol [35] (Figure 7). We identified the two compounds by comparing to the standard substances which were isolated from the defatted fruit of I. polycarpa and identified by mass spectrometry in our laboratory [36]. The antioxidant activities and cell cytotoxicity of two new monomers have been proven [36]. Our findings are consistent with the previous studies and demonstrate that the defatted fruit of I. polycarpa acts as a natural product for ameliorating NAFLD.

Oxidative stress plays a key role in causing the NAFLD process. High activity molecules such as reactive oxygen (ROS) and reactive nitrogen (RNS) free radicals caused an imbalance between prooxidant and antioxidant chemical species that led to oxidative damage of cellular macromolecules $[37,38]$. A previous study has reported that polyphenols can reduce the production of ROS and RNS [39]. The MDA, SOD, and T-AOC are important enzymes of the endogenous antioxidant defense system. Our results showed that EF-D decreases the level of MDA and increases the activities for SOD and T-AOC. Thus, the antioxidant capacity of EF-D seems to have an important connection with treating NAFLD. It has been reported that polyphenols through activation of Nrf2-ARE signal pathways respond to oxidative 


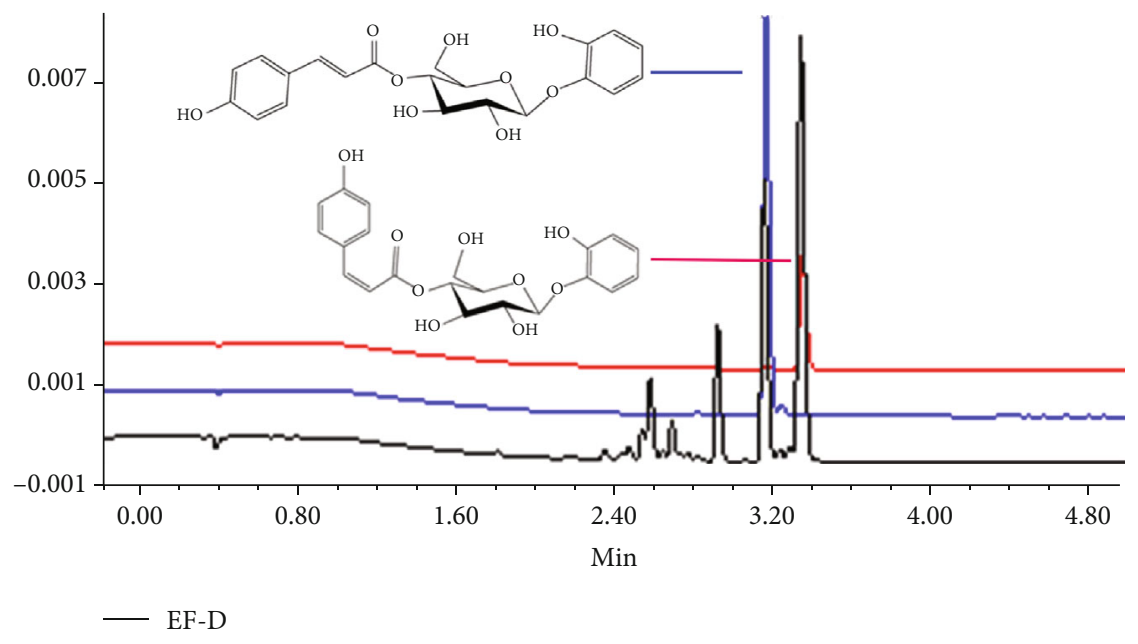

Figure 7: UPLC chromatograms of EF-D and two monomers detected at $280 \mathrm{~nm}$.

stress for inhibiting lipid accumulation [40]. Furthermore, $\mathrm{Nrf} 2$ promotes the activation of downstream relative target genes, such as HO-1, NQO1, CAT, and GSTA2, leading to improved oxidative stress resistance [41]. The expression of genes can influence the generation of relative protease which further regulated related metabolic pathways. It has been demonstrated that genetic control of all characters is mediated through specific enzymes. More precisely, the message of the gene is ultimately carried out by the enzymes [42]. Our results indicated that EF-D could decrease OA-induced oxidative damage through activation of the Nrf2 signaling pathway.

It has been reported that SCD can regulate lipid metabolism and further affect insulin sensitivity [43]. CPT1 is a key regulatory enzyme and rate-limiting enzyme for the betaoxidation of long-chain fatty acids in liver tissues and cells, which is closely related to the catabolism pathway of fatty acids. Earlier studies showed PPARs were target genes for remission in multiple pathways that are disrupted in NAFLD [44]. In particular, PPAR $\alpha$ is located primarily in the liver, adipose tissue, kidney, heart, skeletal muscle, and large intestine where it is thought to regulate the fatty acid synthesis and oxidation, gluconeogenesis, ketogenesis, and lipoprotein assembly [45]. Besides, studies have demonstrated that inflammatory metabolism is closely related to oxidative injury and lipid metabolism [46]. In our experiments, EF-D decreased the mRNA expression of SCD, NF- $\kappa$ B, and IL-1 and increased the mRNA expression of CPT1 and PPAR $\alpha$. Taking the above results together, EF-D inhibited inflammation and improved lipid metabolism disorders through activating PPAR $\alpha$ and Nrf2 antioxidant pathways.

\section{Conclusion}

In conclusion, EF-D can improve the disturbance of lipid metabolism and inflammation in OA-induced hepatic steatosis in HepG2 cells through strong antioxidant activity. Moreover, the mechanism was achieved through regulating relative metabolic enzyme activities and activating PPAR $\alpha$ and Nrf2 antioxidant signal pathways. Evidences collected in this research suggested that EF-D is beneficial for lipidlowering and acts as a candidate medicine for ameliorating NAFLD.

\section{Data Availability}

The data used to support the findings of this study are included within the article.

\section{Conflicts of Interest}

The authors declare no conflict of interest.

\section{Authors' Contributions}

$\mathrm{Na} \mathrm{Li}$ and Yi-ran Sun accomplished the experiment and wrote the paper. Li-bo He, Lei Huang, and Ting-ting Li participated in accomplishing the experiment. Lin Tang provided the financial support for the experiment. $\mathrm{Na} \mathrm{Li}$ and Yi-ran Sun contributed equally to this work.

\section{Acknowledgments}

We are grateful for financial support from the project Sichuan Science and Technology (grant: 18KPPX0137) and the project Luzhou Science and Technology (grant: 2016CDLZ-N20).

\section{References}

[1] M. Suárez, N. Boqué, J. del Bas, J. Mayneris-Perxachs, L. Arola, and A. Caimari, "Mediterranean diet and multi-ingredient based interventions for the management of non-alcoholic fatty liver disease," Nutrients, vol. 9, no. 10, article 1052, 2017.

[2] X. Zhang, X. Ji, Q. Wang, and J. Z. Li, "New insight into interorgan crosstalk contributing to the pathogenesis of nonalcoholic fatty liver disease NAFLD," Protein \& Cell, vol. 9, no. 2, pp. 164-177, 2018. 
[3] Y. Sumida, E. Niki, Y. Naito, and T. Yoshikawa, "Involvement of free radicals and oxidative stress in NAFLD/NASH," Free Radical Research, vol. 47, no. 11, pp. 869-880, 2013.

[4] C. Podrini, M. Borghesan, A. Greco, V. Pazienza, G. Mazzoccoli, and M. Vinciguerra, "Redox homeostasis and epigenetics in non-alcoholic fatty liver disease (NAFLD)," Current Pharmaceutical Design, vol. 19, no. 15, pp. 27372746, 2013.

[5] J. Yan, J. Jiang, L. He, and L. Chen, "Mitochondrial superoxide/hydrogen peroxide: an emerging therapeutic target for metabolic diseases," Free Radical Biology \& Medicine, vol. 152, pp. 33-42, 2020.

[6] J. Simon, M. Nuñez-García, P. Fernández-Tussy et al., “Targeting hepatic glutaminase 1 ameliorates non-alcoholic steatohepatitis by restoring very-low-density lipoprotein triglyceride assembly," Cell Metabolism, vol. 31, no. 3, pp. 605-622.e10, 2020.

[7] M. I. Ahmad, M. U. Ijaz, M. Hussain et al., "High fat diet incorporated with meat proteins changes biomarkers of lipid metabolism, antioxidant activities, and the serum metabolomic profile in Glrx1 mice," Food \& Function, vol. 11, no. 1, pp. 236-252, 2020.

[8] B. Gross, M. Pawlak, P. Lefebvre, and B. Staels, "PPARs in obesity - induced T2DM, dyslipidaemia and NAFLD," Nature Reviews Endocrinology, vol. 13, no. 1, pp. 36-49, 2017.

[9] V. Souza-Mello, D. C. Magliano, T. C. L. Bargut, M. B. Aguila, and C. A. Mandarim-de-Lacerda, "1298 targeting PPARS by bezafibrate alleviates obesity-NAFLD and insulin resistance due to maternal obesity in mice," Journal of Hepatology, vol. 58, no. 1, p. S524, 2013.

[10] F. X. Yang, Y. Q. Su, X. H. Li, Q. Zhang, and R. C. Sun, "Preparation of biodiesel from Idesia polycarpa var. vestita fruit oil," Industrial Crops and Products, vol. 29, no. 2-3, pp. 622-628, 2009.

[11] Z. Zhu, Q. Wang, X. Ruan et al., "Analysis of oil rate and fatty acids content of Idesia palycarpa fruits from different geographical populations," Scientia Silvae Sinicae, vol. 46, no. 5, pp. 176-180, 2010.

[12] M. Lee, H. H. Lee, J. K. Lee, S. K. Ye, S. H. Kim, and S. H. Sung, "Corrigendum to "Anti-adipogenic activity of compounds isolated from Idesia polycarpa on 3T3-L1 cells" [Bioorg. Med. Chem. Lett. 23 (2013) 3170-3174]," Bioorganic \& Medicinal Chemistry Letters, vol. 23, no. 16, pp. 4725-4725, 2013.

[13] M. H. Jung, J. M. Yoo, Y. J. Kang et al., "Idesolide, an isolate of Idesia polycarpa, inhibits apoptosis through induction of intracellular heat shock protein 70 in C2C12 muscle cells," Biological \& Pharmaceutical Bulletin, vol. 33, no. 6, pp. 1063-1066, 2010.

[14] Y. Ye, X. S. Tang, F. Chen, and L. Tang, "Optimization of phenolics extracted from Idesia polycarpa defatted fruit residue and its antioxidant and depigmenting activity in vitro and in vivo," Evidence-based Complementary and Alternative Medicine, vol. 2014, Article ID 931269, 12 pages, 2014.

[15] E. M. Brunt, D. E. Kleiner, L. A. Wilson et al., "Portal chronic inflammation in nonalcoholic fatty liver disease (NAFLD): a histologic marker of advanced NAFLD-clinicopathologic correlations from the nonalcoholic steatohepatitis clinical research network," Hepatology, vol. 49, no. 3, pp. 809-820, 2009.

[16] M. Arrese, D. Cabrera, A. M. Kalergis, and A. E. Feldstein, "Innate immunity and inflammation in NAFLD/NASH,"
Digestive Diseases and Sciences, vol. 61, no. 5, pp. 1294-1303, 2016.

[17] R. Fu, Y. Zhang, Y. Guo, F. Liu, and F. Chen, "Determination of phenolic contents and antioxidant activities of extracts of Jatropha curcas 1 . seed shell a by-product a new source of natural antioxidant," Industrial Crops and Products, vol. 31, no. 5, pp. 265-270, 2017.

[18] X. P. Perea-Domínguez, L. G. Espinosa-Alonso, F. Hosseinian, M. Hadi Nezhad, M. Valdez-Morales, and S. Medina-Godoy, "Phenolic profile and antioxidant activity from non-toxic Mexican Jatropha curcas l. shell methanolic extracts," Natural Product Research, vol. 31, no. 5, pp. 1-5, 2017.

[19] M. G. Miguel, S. Nunes, S. A. Dandlen, A. M. Cavaco, and M. D. Antunes, "Phenols, flavonoids and antioxidant activity of aqueous and methanolic extracts of propolis (Apis mellifera L.) from Algarve, South Portugal," Food Science and Technology, vol. 34, no. 1, pp. 16-23, 2014.

[20] P. T. Tuyen, T. D. Xuan, D. T. Khang et al., "Phenolic compositions and antioxidant properties in bark, flower, inner skin, kernel and leaf extracts of Castanea crenata Sieb. et Zucc," Antioxidants, vol. 6, no. 2, pp. 31-38, 2017.

[21] B. Payet, "Assessment of antioxidant activity of cane brown sugars by ABTS and DPPH radical scavenging assays: determination of their polyphenolic and volatile constituents," Journal of Agricultural \& Food Chemistry, vol. 53, no. 26, pp. 1007410079, 2005.

[22] N. A. Al-Shabib, J. M. Khan, M. S. Ali et al., "Exploring the mode of binding between food additive "butylated hydroxytoluene (BHT)" and human serum albumin: spectroscopic as well as molecular docking study," Journal of Molecular Liquids, vol. 230, pp. 557-564, 2017.

[23] J. A. Jacob, H. S. Mahal, T. Mukherjee, and S. Kapoor, "Free radical reactions with the extract of brassica family," Food Chemistry, vol. 129, no. 3, pp. 1132-1138, 2011.

[24] J. K. Amamcharla and L. E. Metzger, "Modification of the ferric reducing antioxidant power (FRAP) assay to determine the susceptibility of raw milk to oxidation," International Dairy Journal, vol. 34, no. 2, pp. 177-179, 2014.

[25] A. P. Levene, H. Kudo, M. J. Armstrong et al., "Quantifying hepatic steatosis - more than meets the eye," Histopathology, vol. 60, no. 6, pp. 971-981, 2012.

[26] R. Koopman, G. Schaart, and M. K. Hesselink, “Optimisation of oil red o staining permits combination with immunofluorescence and automated quantification of lipids," Histochemistrye Cell Biology, vol. 116, no. 1, pp. 63-68, 2011.

[27] H. Yadav, S. Jain, M. Yadav, P. R. Sinha, G. B. K. S. Prasad, and F. Marotta, "Epigenomic derangement of hepatic glucose metabolism by feeding of high fructose diet and its prevention by rosiglitazone in rats," Digestive and Liver Disease, vol. 41, no. 7, pp. 500-508, 2009.

[28] Y. H. Lee, J. H. Kim, C. H. Song et al., "Ethanol extract of Ganoderma lucidum augments cellular antioxidant defense through activation of Nrf2/HO-1," Journal of Pharmacopuncture, vol. 19, no. 1, pp. 59-69, 2016.

[29] L. S. Zhou, S. Q. Yan, X. L. Xiong, J. Huang, L. L. Zhang, and J. Q. Tang, "Effect of Psoralea corylifolia in treating fatty liver disease in juvenal mouse by inhibiting hepatic NF- $\kappa$ B activation," China journal of Chinese materia medica, vol. 42, no. 13, pp. 2546-2551, 2017.

[30] R. Karbalaei, M. Allahyari, M. Rezaei-Tavirani, H. AsadzadehAghdaei, and M. R. Zali, "Protein-protein interaction analysis 
of Alzheimer's disease and NAFLD based on systems biology methods unhide common ancestor pathways," Gastroenterology \& Hepatology from Bed to Bench, vol. 11, no. 1, pp. 2733,2018

[31] M. Hęś, D. K, D. Górecka, A. Jędrusek-Golińska, and E. Gujska, "Aloe vera (l.) webb.: natural sources of antioxidants - a review," Nutrition, vol. 74, pp. 255-265, 2019.

[32] A. H. Zhang, H. Sun, and X. J. Wang, "Recent advances in natural products from plants for treatment of liver diseases," ChemInform, vol. 63, no. 33, pp. 570-577, 2013.

[33] S. Mignani, J. Rodrigues, H. Tomas et al., "Dendrimers in combination with natural products and analogues as anti-cancer agents," Chemical Society Reviews, vol. 22, no. 47, pp. 514$532,2018$.

[34] C. P. Wong, T. Kaneda, and H. Morita, "Plant natural products as an anti-lipid droplets accumulation agent," Journal of Natural Medicines, vol. 68, no. 2, pp. 253-266, 2014.

[35] F. Feistel, C. Paetz, S. Lorenz, F. Beran, G. Kunert, and B. Schneider, "Idesia polycarpa (Salicaceae) leaf constituents and their toxic effect on Cerura vinula and Lymantria dispar (Lepidoptera) larvae," Phytochemistry, vol. 143, pp. 170-179, 2017.

[36] L. Huang, T. Peng, Y. Li et al., "A new phenolic glycoside from the Idesia polycarpa Maxim. leaves," Natural Product Research, vol. 33, no. 20, pp. 3016-3020, 2019.

[37] S. M. Zain, Z. Mohamed, M. Pirmohamed et al., "Copy number variation in exportin-4 (XPO4) gene and its association with histological severity of non-alcoholic fatty liver disease," Scientific Reports, vol. 5, no. 1, p. 13306, 2015.

[38] K. J. A. Lemmens, B. van de Wier, G. H. Koek et al., "The flavonoid monoHER promotes the adaption to oxidative stress during the onset of NAFLD," Biochemical and Biophysical Research Communications, vol. 456, no. 1, pp. 179-182, 2015.

[39] X. Qiang, L. Xu, M. Zhang et al., "Demethyleneberberine attenuates non-alcoholic fatty liver disease with activation of AMPK and inhibition of oxidative stress," Biochemical and Biophysical Research Communications, vol. 472, no. 4, pp. 603-609, 2016.

[40] J. Zhou, C. T. Ho, P. Long, Q. Meng, L. Zhang, and X. Wan, "Preventive efficiency of green tea and its components on non-alcoholic fatty liver disease," Journal of Agricultural and Food Chemistry, vol. 67, no. 19, pp. 5306-5317, 2019.

[41] Y. Zhou, Y. L. Ding, J. L. Zhang, P. Zhang, J. Q. Wang, and Z. H. Li, "Alpinetin improved high fat diet-induced nonalcoholic fatty liver disease (NAFLD) through improving oxidative stress, inflammatory response and lipid metabolism," Biomedicine \& Pharmacotherapy, vol. 97, pp. 1397-1408, 2018.

[42] J. K. Bhattacharjee and A. K. Sinha, "Relationship among the genes, enzymes, and intermediates of the biosynthetic pathway of lysine in Saccharomyces," MGG-Molecular and General Genetics, vol. 115, no. 1, pp. 26-30, 1972.

[43] M. A. Lounis, S. Lalonde, S. A. Rial et al., "Hepatic BSCL2 (Seipin) deficiency disrupts lipid droplet homeostasis and increases lipid metabolism via SCD1 activity," Lipids, vol. 52, no. 5, pp. 1-22, 2016.

[44] H. Tutunchi, A. Ostadrahimi, M. Saghafi-Asl, and V. Maleki, "The effects of oleoylethanolamide, "an endogenous PPAR $\alpha$ agonist, on risk factors for NAFLD: a systematic review,", Obesity Reviews, vol. 20, no. 7, pp. 1057-1069, 2019.
[45] J. Ju, Q. Huang, J. Sun et al., "Correlation between PPAR- $\alpha$ methylation level in peripheral blood and atherosclerosis of NAFLD patients with DM," Experimental \& Therapeutic Medicine, vol. 15, no. 3, pp. 2727-2730, 2018.

[46] C. Li, Q. Liu, and L. Xie, "Suppressing NLRP2 expression accelerates hepatic steatosis: a mechanism involving inflammation and oxidative stress," Biomedicine \& Pharmacotherapy, vol. 507, no. 1, pp. 22-29, 2018. 